\title{
“CONVERTER" NATUREZA EM CULTURA? O MUNDO NATURAL E AS NOVAS SENSIBILIDADES EM RELAÇÃO AOS ANIMAIS, Às PLANTAS E À PAISAGEM
}

\author{
Carina Santos de Almeida*
}

THOMAS, Keith. O homem e o mundo natural: mudanças de atitude em relação às plantas e aos animais (1500 - 1800). Tradução João Roberto Martins Filho. São Paulo: Companhia das Letras, 2010 [1983].

Uma das indagações realizadas pelo historiador social Keith Thomas em seu destacado livro editado pela primeira vez em 1983 se refere a "[...] como teria progredido a civilização sem a limpeza das flores, o cultivo do solo e a conservação da paisagem agreste em terra colonizada pelo homem?" Sem indicar respostas imediatas, Thomas analisa as complexas posturas que a sociedade inglesa demonstrou frente ao mundo natural de 1500 até 1800 e como em decorrência destas emergiu novas sensibilidades frente aos animais, às plantas e à paisagem. Ao longo do período moderno ocorreram transformações na maneira como se percebia e se classificava o mundo natural, por mais que seja impossível desemaranhar o que a sociedade pensava sobre as plantas e os animais daquilo que entendia de si mesma, o predomínio humano sobre o mundo vegetal e animal se constituiu e se constitui numa precondição básica da história humana.

Este livro de Thomas, editado no Brasil pela primeira vez em 1988, representa uma versão ampliada das palestras proferidas nas Conferências George Macaulay Trevelyan, na Universidade de Cambridge, em 1979. O homem e o mundo natural se configura num livro singular sobre a história das relações da sociedade europeia com o mundo natural, vegetal, animal e a paisagem, porém, esgotado há alguns anos em nosso país, foi reeditado em

\footnotetext{
* Doutoranda no Programa de Pós-Graduação em História da Universidade Federal de Santa
} Catarina - UFSC e bolsista REUNI/MEC.E-mail: carina_almaid@yahoo.com.br 
"Converter" natureza em cultura? o mundo natural e as novas sensibilidades em

relação aos animais, às plantas e à paisagem

2010 numa versão de bolso da Companhia das Letras. Apesar de pertencer ao contexto da década de 1980, a abordagem de Thomas não foi superada e se apresenta atual a medida que poucos são os historiadores que atentam para as relações entre o homem e a natureza. Por muito tempo existiu, seja na teologia como na filosofia e em certa medida nas ciências naturais, uma subserviência da natureza frente a cultura e um demérito do mundo vegetal e animal em relação a humanidade. As análises desveladas por Keith Thomas estão longe de serem encerradas e permanecem inspirando muitos historiadores brasileiros.

O livro de Thomas apresenta seis capítulos, no primeiro o historiador discute o predomínio humano a partir da antropocêntrica visão de mundo, baseada nos fundamentos teológicos, bem como na sujeição do mundo natural, na singularidade humana, na conservação de fronteiras entre homem e mundo natural e na existência de seres humanos inferiores. No segundo capítulo, chamado história natural e erros vulgares, Thomas escreve sobre as formas de classificação, os erros vulgares, a nomenclatura e as perspectivas de mudança em relação ao mundo natural. No terceiro capítulo, aborda os homens e animais, descreve como surge a noção de companheiros domésticos e espécies privilegiadas, da mesma forma que a diminuição da distância entre homem e animais e a compreensão da existência de almas animais. $\mathrm{O}$ historiador menciona a compaixão pelas criaturas brutas, a noção de crueldade, os novos argumentos e o destronamento do homem, as novas sensibilidades e as emergentes condições do período moderno em seu quarto capítulo. Numa quinta parte, árvores e flores, comenta sobre o que a sociedade compreendia como mata virgem, os motivos para o plantio de árvores, bem como o nascimento de certo culto as árvores e as flores. Seu último capítulo disserta sobre o dilema humano por meio de antagonismos como cidade ou campo, lavoura ou terra inculta, conquista ou preservação, morte ou mercê, estabelecendo por fim, algumas considerações finais.

Na cosmologia do mundo ocidental o Jardim do Éden, conhecido como paraíso, foi preparado para o homem, Deus havia conferido a Adão o domínio sobre todas as coisas vivas. O pecado original mudou esta relação e o homem perdeu o direito de exercer domínio fácil e inconteste sobre as outras espécies. Entre 1500 e 1800 ocorreu uma série de transformações na maneira pela qual homens e mulheres percebiam e classificavam o mundo natural ao seu redor. Foi no final do século XVII e início do XVIII que estes debates atingiram forma mais engenhosa e extravagante. Para Thomas, Karl Marx indicara que não foi a religião que conduziu o homem a exploração do mundo natural, mas sim o surgimento da propriedade privada e da economia monetária: “[...] 'a grande influência civilizadora do capital' que, finalmente, pôs fim à 'deificação da natureza' "'(p. 30). 
Animais e plantas eram maleáveis à civilização humana, e esta última, sinônimo de conquista da natureza. Assumiu-se uma polaridade entre homem e animal, e neste contexto, elaborou-se a convicção de que o homem e a humanidade eram formas de vida mais elaboradas. Forjou-se uma diferença qualitativa entre o homem - belo e perfeito - e os seres brutos. Portanto, cabia evitar os impulsos animais, conservando as fronteiras, afastando associações indesejáveis como "estalar os lábios como um cavalo", "engolir a comida sem mastigar" e "lamber o prato como um felino". Era bestial que o homem tivesse o cabelo indevidamente longo, “[...] 'Os bichos são mais peludos que o homem' escrevia Bacon, 'e os homens selvagens mais que os civilizados' " (p. 51). Outra forma de bestialidade era a nudez, as roupas e o ato de cozinhar eram atributos exclusivos do homem. Desaprovavam-se relações de proximidade com os animais, foi a partir deste período que a maior parte dos agricultores colocaram estes para fora de suas casas.

O animais ofereciam uma reserva inesgotável de significados simbólicos, xingar alguém com a expressão "animal" fazia parte do discurso cotidiano, qualquer homem que não demonstrasse qualidades seria sub-humano ou semianimal. Por volta dos seiscentos e setecentos muitos discursos sobre a "natureza animal dos negros" evidenciavam sua sexualidade animalesca e brutal, ${ }^{1}$ os índios americanos, em geral, não eram vistos dessa forma, mas isso não impediu que fossem muitas vezes descritos em linguagem semelhante. Essas concepções encaminharam a humanidade para a afirmação de que a cultura era tão necessária ao homem como a domesticação de animais e plantas. Pobres, vagabundos, muitas vezes crianças, mulheres, jovens e loucos eram "bestiais" e se aproximavam de um "estado animal".

O nascimento da história natural e a influência de botânicos e zoólogos se manifestou, sobretudo, por meio do processo de classificação que minou os antigos pressupostos e acarretou no surgimento dos estudos científicos acerca dos animais e plantas. Os primeiros zoólogos modernos herdaram de Aristóteles a prática de classificação em estrutura anatômica, habitat e modo de reprodução. Aos poucos, as plantas foram consideradas pelo gosto, cheiro, comestíveis e com valor medicinal, isso indica que os primeiros botânicos foram compreendidos como médicos ou boticários.

De forma geral, entre 1500 e 1800, havia três categorias de animais, comestíveis e não-comestíveis, ferozes e mansos (selvagem e domesticado) e úteis e inúteis (para os homens). Tais categorias oscilavam de um século ao outro, mas havia um consenso de que era proibido matar animais indispensáveis ao trabalho. Por outro lado, havia muitas formas de nominar as plantas. Apesar dos primeiros progressos da história natural se dever à sabedoria popular, exigia-se uma taxonomia neutra que substituísse os métodos de classificação antropocêntricos. Neste contexto, em 1735 foi desenvolvido o sistema Lineano 
"Converter" natureza em cultura? o mundo natural e as novas sensibilidades em relação aos animais, às plantas e à paisagem

(Lineu) que propôs uma classificação baseada na descendência como critério essencial - ainda que Lineu pressupusesse a mutabilidade da espécie, até este cientista misturava descrições zoológicas com juízos morais e estéticos. A nomenclatura Lineana com a introdução da nova terminologia latina aumentou o abismo entre os modos popular e o erudito de ver o mundo da natureza.

Havia uma analogia e metáforas animais no discurso cotidiano. Porém, isso logo foi sendo erodido a medida que se deu o crescimento das cidades e das indústrias. Por outro lado, nem todos os animais ocupavam o mesmo papel na sociedade, algumas espécies eram privilegiadas, como o cavalo, os gatos e o cão (preferido entre todos os animais). Foi a partir dos estudos geológicos e arqueológicos que a história do desenvolvimento humano começou a considerar que o tempo de existência da Terra era infinitamente mais extenso do que se pensava, aos poucos começou a se fundar as ideias de evolução humana e dos meios eugênicos na noção de ser humano, visto que havia um conjunto de criaturas bestiais e muitas vezes híbridas no imaginário dos homens, portanto, o hibridismo era visto como algo bizarro. No século XVIII emergiu a doutrina racista, assim, dever-se-ia evitar o "cruzamento humano", inclusive entre brancos com negros, porquanto isso causava deformidade e degeneração da raça.

A compaixão pelas criaturas brutas partiu de questionamentos quanto ao tratamento dos animais, como a proximidade e a crueldade. A prática de esportes no campo como perseguição e eliminação de animais selvagens obcecou por muito tempo a aristocracia, aos poucos esta prática passou a ser contestada, apesar de emanar status. Existia na sociedade inglesa dois tipos de crueldade, a proveniente do descuido ou indiferença e a do espírito de vingança, mas a mais comum era a indiferença. Aos poucos surgiram novas sensibilidades, sobretudo contra o sofrimento dos animais, como em "brigas" para divertimento. Os animais passaram a ser compreendidos como seres sensíveis, ainda assim, novas condições foram emergindo, como cidades, industrialização, animais para trabalho, portanto, com valor econômico. A sociedade ocidental percebeu o destronamento do homem e que o mundo não existe somente para este, essa aceitação explícita certamente foi uma das grandes revoluções no moderno pensamento ocidental.

O mundo da natureza deixou de ser mera criação bruta, surgiram novos sentimentos no período moderno. A partir dos setecentos o paisagismo tornouse passatempo dos abastados, com isso, certa paixão pelo cultivo de flores se difundiu pela sociedade. Mas a floresta de certa forma foi considerada selvagem e hostil, sinônimo de rusticidade e perigo, a baixa das matas simbolizava o triunfo da civilização e o homem que vivia nas matas era compreendido como rude e bárbaro. O progresso da humanidade se sucedeu no sentido floresta para o campo, somente "[...] se retirando das florestas os homens seriam levados à 
"Converter" natureza em cultura? o mundo natural e as novas sensibilidades em

relação aos animais, às plantas e à paisagem

civilidade" (p. 276). Se as matas eram concebidas como obstáculo ao progresso humano, o reflorestamento ordenado e organizado era considerado como domesticação: surgia a teoria da estética dominante com ênfase na árvore como parte essencial do cenário arquitetônico. O termo floresta era polissêmico, podia significar hostil, mas também mata reflorestada, utilizada para retirar madeira e que abrigava tanto gado quanto cervos.

Aos poucos o culto das árvores, mas árvores plantadas e ordenadas, ou seja, domesticadas, tomou conta do mundo moderno. A árvore se consolidou como exemplo de simbologia genealógica e de descendência. O carvalho virou símbolo nacional na Inglaterra. Com isso, o jardim inglês passou a ser o lugar da reflexão espiritual, tanto na vida como na literatura. O jardineiro e o paisagista - novas profissões - passaram a imputar certo desejo estético por flores, mas flores ordenadas é claro.

A emergência de novas sensibilidades na sociedade europeia e inglesa do período moderno se concretizou a medida que o dilema humano por meio do estudo da história natural reviu percepções antropocêntricas dos tempos anteriores. Ainda que o "gosto" oscilasse entre cidade ou campo e na Renascença a cidade fosse sinônimo de civilidade enquanto o campo de rudeza e rusticidade, em 1800, o campo passou a ser mais bonito que a cidade, ao certo, mais virtuoso. Entre o dilema da lavoura ou terra inculta ocorreram mudanças fundamentais nas sensibilidades, a paisagem domesticada, habitada e produtiva, representava beleza e fertilidade. A aradura trouxe simetria à natureza, a prática de plantar não representava apenas um modo eficiente de aproveitar o espaço escasso, mas um meio agradável de "[...] impor ordem humana ao mundo natural desordenado. [...]" (p. 362).

O historiador Thomas afirma que uma das características humanas sempre foi a de separar cultura e natureza, seja por meio de padrões formais, simetria ou esmero. Parece que no período moderno essa tendência no mínimo aumentou consideravelmente. Uma bela região era uma região domesticada. $\mathrm{O}$ "gosto" continuou se adaptando ao corrente pensamento moderno, antes mesmo de findar o século XVIII, o jardim inglês não era mais àquele aparado de forma simétrica, mas àquele que aos poucos se amparava na jardinagem informal como renovação espiritual, quanto mais "[...] selvagem fosse a cena, maior o poder de inspirar emoção. [...]” (p. 366). O gosto pelo sublime foi se evidenciando como uma espécie de agradável horror ao mesmo tempo em que se recorria a divinização da natureza. A construção da paisagem selvagem foi um fenômeno europeu que incluía tanto pensadores como Rousseau e Von Humbold, mas, sobretudo, intelectuais ingleses. Certo estilo natural e jardinagem paisagística se tornaram aquisições culturais na Inglaterra.

A despeito das sensibilidades estéticas revalorizarem o mundo natural, estas foram agredidas pela conquista humana da natureza. O próprio 
"Converter" natureza em cultura? o mundo natural e as novas sensibilidades em

relação aos animais, às plantas e à paisagem

vegetarianismo surgiu como uma espécie de constrangimento diante da ideia de morte ou mercê da alimentação carnívora em fins do século XVIII, impondo certa tonalidade radical às novas sensibilidades. Por fim, encerro esta resenha com palavras de Keith Thomas que reforçam a importância de sua obra, ressaltam a originalidade e a atualidade de seu pensamento no mundo hodierno:

[...] o começo do período moderno gerou sentimentos que tornariam cada vez mais difícil os homens manterem os métodos implacáveis que garantiram a dominação de sua espécie. Por outro lado, eles viram um aumento incalculável do conforto, bem-estar e felicidade materiais dos seres humanos; por outro lado, davam-se conta de uma impiedosa exploração de outras formas de vida animada. Havia, dessa maneira, um conflito crescente entre as novas sensibilidades e os fundamentos materiais da sociedade humana. Uma combinação de compromisso e ocultamento impediu até agora que tal conflito fosse amplamente resolvido. É possível afirmar ser essa uma das contradições sobre as quais assenta a civilização moderna. Sobre as suas consequências finais, tudo o que podemos é especular (p. 428).

\section{NOTA}

\footnotetext{
I Sobre a escravidão negra, Thomas evidencia que "Os historiadores consideram atualmente que a escravidão negra precedeu as afirmações da condição semianimal dos negros. As teorias mais desenvolvidas de inferioridade racial vieram depois. Entretanto, é difícil crer que o sistema jamais tivessem sido tolerado se aos negros fossem atribuídos traços totalmente humanos. A desumanização foi um pré-necessário dos maus-tratos" (p. 60). Por outro lado, a "[...] escravidão era atacada porque confundia as categorias homem e animal, enquanto se denunciava a tirania política com o argumento de que era errado tratar seres humanos como se fossem animais. [...] A razão governa o homem, declarava John Locke. A força era apenas para os seres brutos" (p. 65 e 66).
}

Resenha recebida em agosto de 20 I I. Aceita em agosto de 201 I. 